\title{
Method for Vigor Diagnosis of Tea Trees based on Nitrogen Content in Tealeaves Relating to NDVI
}

\author{
Kohei Arai ${ }^{1}$ \\ ${ }^{1}$ Graduate School of Science and Engineering \\ Saga University \\ Saga City, Japan
}

\begin{abstract}
Method for vigor diagnosis of tea trees based on nitrogen content in tealeaves relating to NDVI is proposed. In the proposed method, NIR camera images of tealeaves are used for estimation of nitrogen content in tealeaves. The nitrogen content is highly correlated to Theanine (amid acid) content in tealeaves. Theanine rich tealeaves taste good. Therefore, tealeaves quality can be estimated with NIR camera images. Also, leaf area of tealeaves is highly correlated to NIR reflectance of tealeaf surface. Therefore, not only tealeaf quality but also harvest mount can be estimated with NIR camera images. Experimental results shows the proposed method does work for estimation of appropriate tealeaves harvest timing with NIR camera images.
\end{abstract}

Keywords-Tealeaves; Nitrigen content; Amino accid; Leaf area; NDVI

\section{INTRODUCTION}

It is highly desired to monitor vitality of crops in agricultural areas automatically with appropriate measuring instruments in order to manage agricultural area in an efficient manner. It is also required to monitor not only quality but also quantity of vegetation in the farmlands. Vegetation monitoring is attempted with red and photographic cameras [1]. Grow rate monitoring is also attempted with spectral observation [2].

This paper deals with automatic monitoring of a quality of tealeaves with earth observation satellite, network cameras together with a method that allows estimation of total nitrogen and fiber contents in tealeaves as an example. Also this paper describes a method and system for estimation of quantity of crop products by using not only Vegetation Cover: VC and Normalized Difference Vegetation Index: NDVI but also Bidirectional Reflectance Distribution Function: BRDF because the VC and NDVI represent vegetated area while BRDF represents vegetation mass, or layered leaves.

Total nitrogen content corresponds to amid acid which is highly correlated to Theanine: 2-Amino-4-(ethylcarbamoyl) butyric acid for tealeaves so that total nitrogen is highly correlated to tea taste. Meanwhile fiber content in tealeaves has a negative correlation to tea taste. Near Infrared: NIR camera data shows a good correlation to total nitrogen and fiber contents in tealeaves so that tealeaves quality can be monitored with network NIR cameras. It is also possible to estimate total nitrogen and fiber contents in leaves with remote sensing satellite data, in particular, Visible and near infrared: VNIR radiometer data. Moreover, VC, NDVI, BRDF of tealeaves have a good correlation to grow index of tealeaves so that it is possible to monitor expected harvest amount and quality of tealeaves with network cameras together with remote sensing satellite data. BRDF monitoring is well known as a method for vegetation growth [3],[4]. On the other hand, degree of polarization of vegetation is attempted to use for vegetation monitoring [5], in particular, Leaf Area Index: LAI together with new tealeaves growth monitoring with BRDF measurements [6].

It is obvious that nitrogen rich tealeaves tastes good while fiber rich tealeaves tastes bad. Theanine: 2-Amino-4(ethylcarbamoyl) butyric acid that is highly correlated to nitrogen contents in new tealeaves are changed to catechin [7],[8],[9] due to sun light. In accordance with sunlight, new tealeaves grow up so that there is a most appropriate time for harvest in order to maximize amount and taste of new tealeaves simultaneously.

Optical properties of tealeaves and methods for estimation of tealeaves quality and harvest amount estimation accuracy are well reported [10]-[17]. The method proposed here is to determine tealeaves harvest timing by using NIR camera images together with meteorological data. By using these relations between NDVI and nitrogen content in tealeaves as well as Theanine, it is possible to estimate vigor of tea trees. During the winter time, tea trees used to maintain their vigor. A good quality of remote sensing satellite data can be acquired during the winter season even if the revisit cycle is poor. Using such a good quality data derived from visible to near infrared radiometers onboard remote sensing satellites, it is capable to estimate vigor of tea trees.

The following section describes the proposed method together with some research background. Then experimental results are described followed by discussions. Finally, conclusions are described together with future research works.

\section{PROPOSED METHOD AND SYSTEM}

\section{A. Proposed System}

Fig. 1 shows the proposed tea farm observation system for evaluation of tealeaf quality and harvest amount as well as vigor diagnosis. It is multi-layered observation system from space (remote sensing satellite), from the lower boundary layer (UAV, or drones), and ground based observation system (Near Infrared: NIR cameras). 


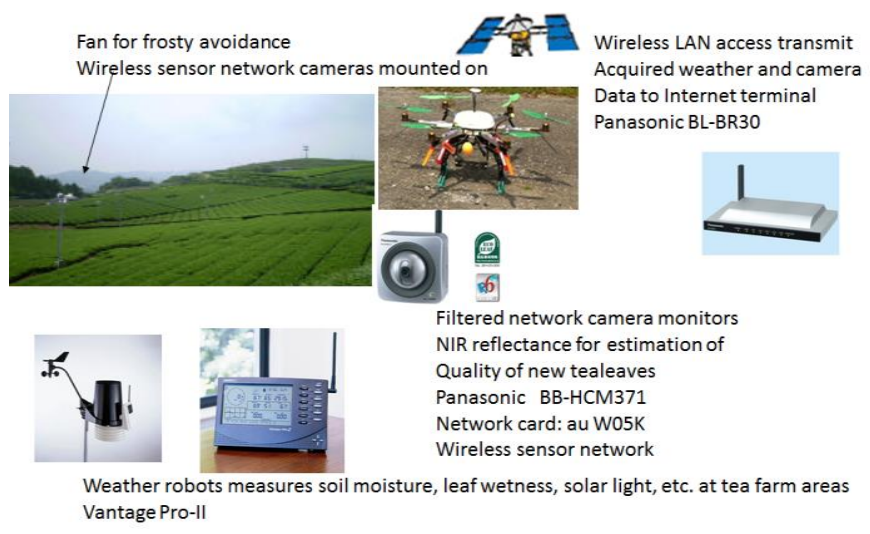

Fig. 1. Proposed tea farm observation system for evaluation of tealeaf quality and harvest amount as well as vigor diagnosis

\section{B. Research Background}

Due to the fact that revisit cycle of remote sensing satellites which carry visible to near infrared radiometer is too long, remote sensing satellite data cannot be used for monitoring the new tealeaf growing stage. Fig.2 shows annual cycle of tealeaf production. New tealeaves are borne in the begging of April. Then it is harvest timing in the begging of May. Therefore, the new tealeaves are used to be grown up within a month or so. Usually, revisit cycle of remote sensing satellites is more than 15 days. Therefore there are two chances to observe tea farm areas during the new tealeaves growing stage. It, however, cannot observe when it is cloudy, rainy with visible to near infrared radiometer onboard satellites. Therefore, it cannot be used for vigor diagnosis with remote sensing satellite data.

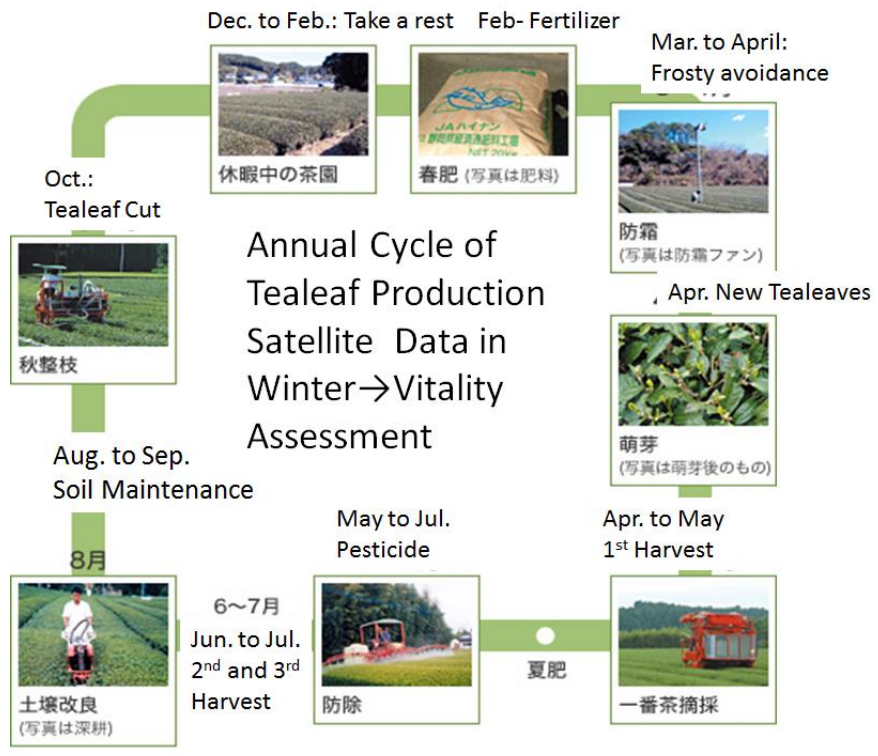

Fig. 2. Annual cycle of tealeaf production

Fig. 3 shows annual cycle of nitrogen content in tealeaves. After the first harvest in the begging of May, pesticide and fertilizer are put in tea farm areas during May to June. Then secondly grown tealeaves can be harvested in June. Then, the thirdly grown tealeaves can also be harvested in July. These three harvest timings are indicated in the Fig.3. Therefore, it is easily understand that the nitrogen content in tealeaves is repeated up and down annually.

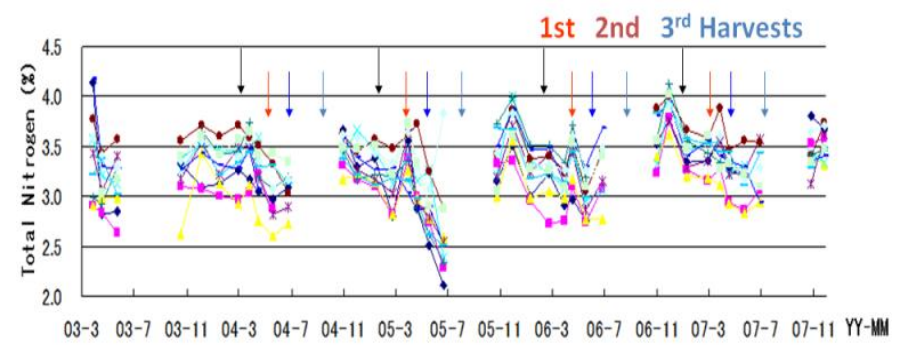

Fig. 3. Annual cycle of nitrogen content in tealeaves

During two months, August and September, soil maintenance has to be done for the future in order to maintain tea trees vitality. More than half of matured tealeaves are cut off in October (it is preparation for winter). Then tea trees take a rest during November to February in the next year. Fertilizer is put into tea farm areas in February. After that, fan is activated during March to April for forestry avoidance (tea trees are very week against forestry). Then new tealeaves are borne again in the latter in March or in the begging of April.

\section{Remote Sensing Satellite Data}

One of examples of visible to near infrared radiometer (ASTER/VNIR) imagery data (Instantaneous Field of View: IFOV is $15 \mathrm{~m}$ ) of remote sensing satellite (Terra) of Saga Prefectural Tea Research Institute (SPTRI): 33:07:3.9 (North), 129:59:47.0 (East), 95m (Elevation) which is acquired on February 2007 is shown in Fig.4 (a) on the right while the google map image is shown in Fig.4 (a) on the left. Also, pansharpened image with ALOS/PRISM is shown in Fig.4 (b) while Normalized Difference Vegetation Index: NDVI image of the pan-sharpened image is shown in Fig.4 (c).

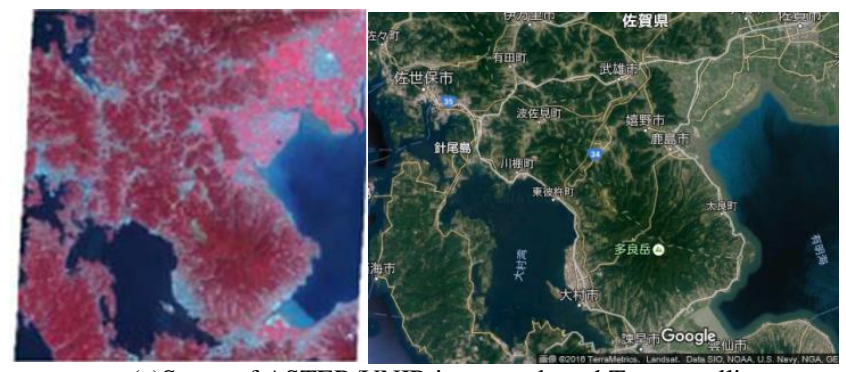

(a)Scene of ASTER/VNIR image onboard Terra satellite

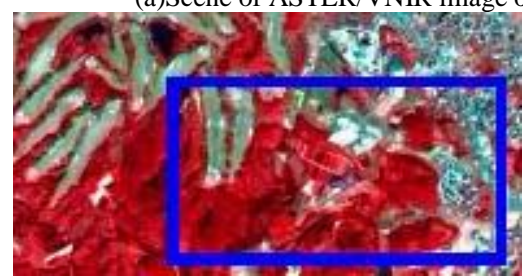

(b)Enlarged portion of pan-sharpened image 


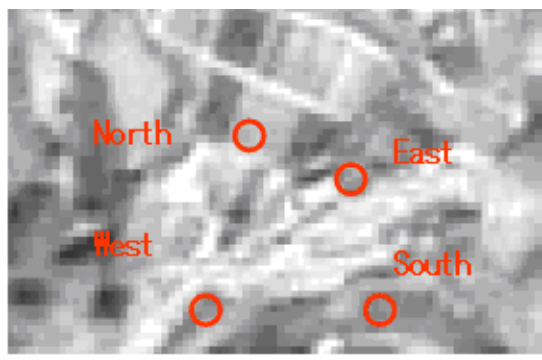

(c)NDVI of the four test sites in SPTRI

Fig. 4. Example of ALOS/AVNIR-2 image and Terra/ASTER/VNIR data of Saga Prefectural Tea Research Institute: SPTRI in Ureshino-city, Saga, Japan which are acquired on February 2007

Pan-sharpened image is derived from the following procedure,

1) ASTER/VNIR imagery data with three bands (Green, Red and Near infrared) is assumed to be color data (RGB).

2) RGB data is converted to Hue, Saturation and Intensity (HSI).

3) The Intensity image is replaced to pan-chromatic ALOS/PRISM imagery data with $2.5 \mathrm{~m}$ of IFOV.

4) Then HSI is converted to RGB reversely.

Thus a high spatial resolution of ASTER/VNIR imagery data can be derived. Using the pan-sharpened imagery data, NDVI imagery data is generated be the following equation,

$\mathrm{NDVI}=(\mathrm{NIR}-\mathrm{VIS}) /(\mathrm{NIR}+\mathrm{VIS})$

As shown in Fig.4 (c), bright portion indicates vital vegetated areas while dark portion indicates poorly vegetated areas. It is well known that there is strong relation between NDVI and nitrogen content in tealeaves (Total Nitrogen: TN) which are closely related to amino-acid, Theanine. Theanine rich tealeaves taste good. Therefore, tealeaf quality can be estimated with NDVI derived from ASTER/VNIR onboard Terra satellite of imagery data. Revisit cycle of Terra satellite is, however, so long, 16 days. Therefore, another monitoring system has to be prepared for growing up period. One of the solutions is ground based camera monitoring system. A single band of camera is much easier than two bands of camera, visible and near infrared to manufacture. Therefore, the relation between $\mathrm{TN}$ and reflectance of tealeaves at near infrared wavelength is investigated together with fiber content in tealeaves. Fiber content indicates tealeaf age. Namely, young tealeaves do not have much fiber (F-NIR: Fiber content measured with NIR radiometry while elder tealeaves are fiber rich. A good quality of tealeaves can be defined as good taste and young tealeaves resulting in $\mathrm{TN}$ rich and poor fiber.

\section{Ground Based Camera Data}

These can be measured with NIR camera. Using YubaFlex camera, the relation between NIR reflectance and TN as well as F-NIR is investigated. Essentially, YubaFlex is designed for NDVI camera. Therefore, visible to near infrared wavelength regions are covered with YubaFlex. The major specifications are as follows,

Cannon Power Shot S100: 1330pixels, 173g

Spectral response for Blue $\rightarrow$ Near Infrared
Spectral response of YubaFlex is shown in Fig.5. As shown in Fig.5, originally assigned spectral response of blue band is replaced to near infrared (Center wavelength of 870 $\mathrm{nm})$. It is useful for NDVI data collections. It, however, does cost. Therefore, another NIR filter film attached camera is prepared for TN and F-NIR measurements.

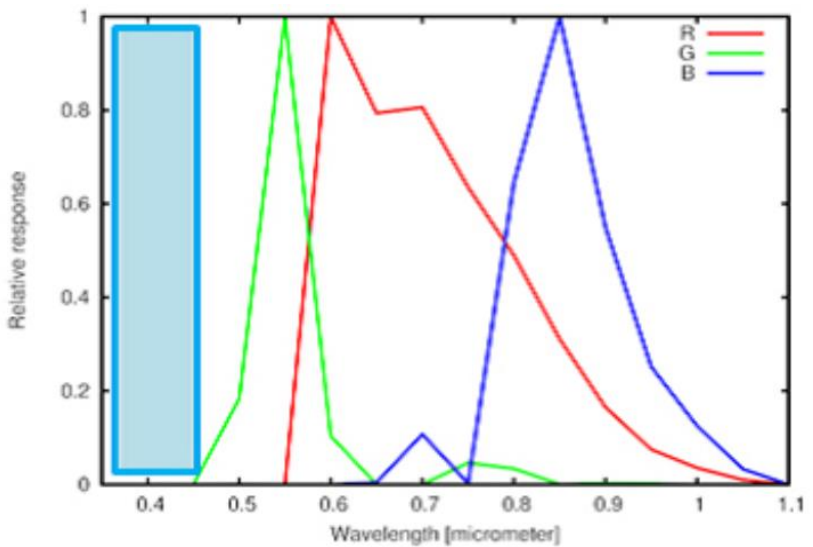

Fig. 5. Spectral of YubaFlex (NIR camera)

Reflectance measurements can be done with standard plaques such as Spectralon manufactured by LabSphere Co. Ltd. in USA. The Spectralon is not so cheap while photo print paper is very cheap. Therefore, photo print paper is used as a standard plaque. In order to compensate the difference between the Spectralon and the photo print paper used, the difference between reflectance of the Spectralon and the photo print paper used is measured. Fig.6 shows outlook of the Spectralon and a small portion of the photo print paper used while Fig.7 shows the difference between both reflectance of the Spectralon and the photo print paper used.

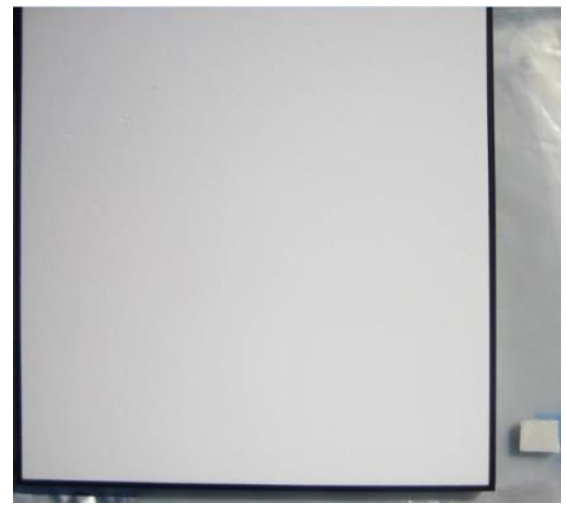

Fig. 6. Outlook of the Spectralon (left) and the photo print paper used (right)

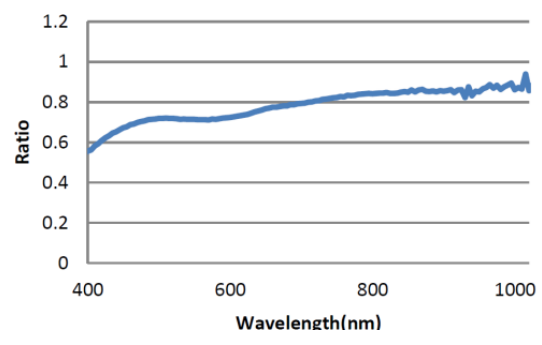

Fig. 7. Ratio of the Spectralon based NIR reflectance and the print sheet based NIR reflectance 


\section{E. Relation between Sensing Satellite Data and Tealeaf Quality}

The relation between NIR reflectance of tealeaves measured at SPTRI on January 152008 and TN as well as FNIR is shown in Fig.8. There are four test sites in the SPTRI, East (Yabukita), South (Oiwase), West (Benifuki), North (Okumidori), N (Yabukita-U), N (Yabukita-D). The names in the bracket denote the names of species while dash $U$ and $D$ denotes upper tea field and down tea field, respectively. Spectral reflectance of the typical tea farm areas in the SPTRI is shown in Fig.9.

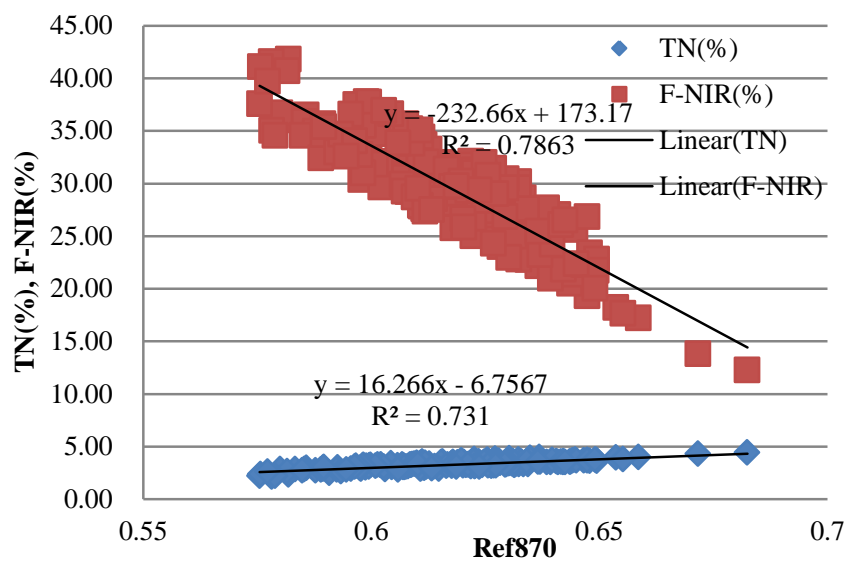

Fig. 8. Relation between NIR reflectance of tealeaves and TN as well as FNIR

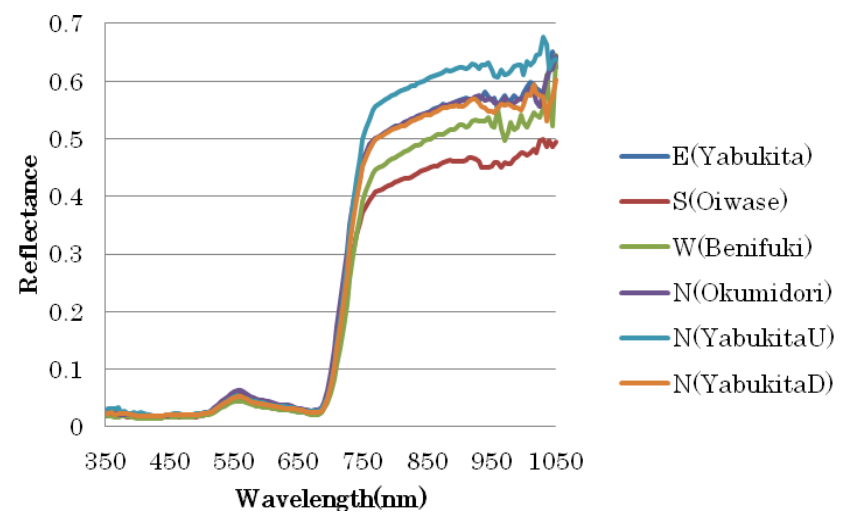

Fig. 9. Spectral reflectance of the typical tea farm areas in the SPTRI

The estimated TN and F-NIR as well as NDVI images can be superimposed on the corresponding geographical maps using Geographic Information System: GIS such as Fig.10. Thus the tea farmers can take a look at the tealeaf quality by field by field and then make fertilizer and pesticide plans as well as harvesting plan (find the best tealeaf quality) with the best weather condition appropriately.

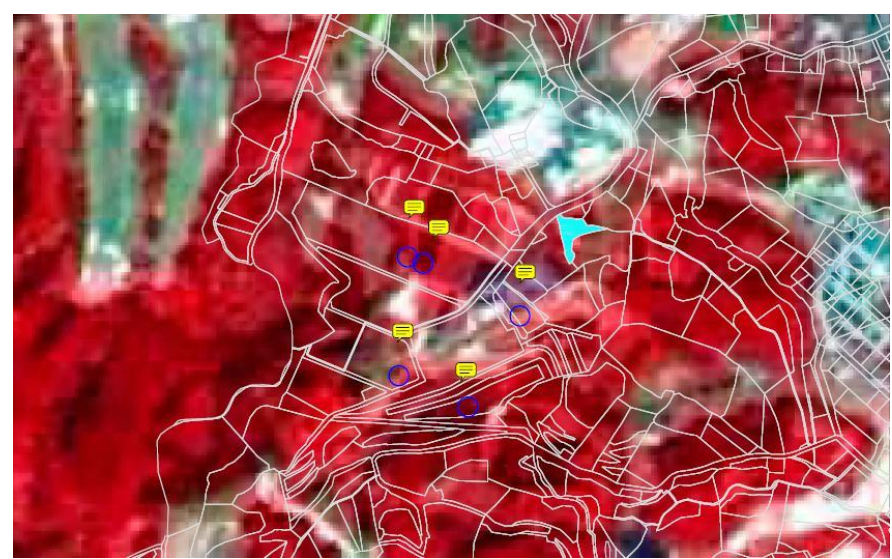

Fig. 10. GIS representation of pan-sharpened image on geographic map (also it is possible to superimpose NDVI, TN, F-NIR images on the same geographic maps)

\section{F. Vigor Diagnosis with remote Sensing Satellite Data}

As mentioned before, tea trees' vigor diagnosis can be done with visible to near infrared radiometer onboard remote sensing satellites. In order for that, a good quality of VNIR image has to be acquired in winter, during October and March next year. The vigor of tea trees is defined as TN content in tealeaves. Therefore, a relation between $\mathrm{TN}$ measured in winter and TN at harvest timing has to be investigated. Fig.11 shows the relation estimated with ASTER/VNIR imagery data as well as ground based camera data measured at SPTRI in 2009. $\mathrm{R}$ square values range from 0.541 to 0.720 depending on the data acquisition date. It is found that just before new tealeaves are borne (February 28 in this case) is the most appropriate timing for satellite data acquisition in order for tea tree vigor diagnosis.

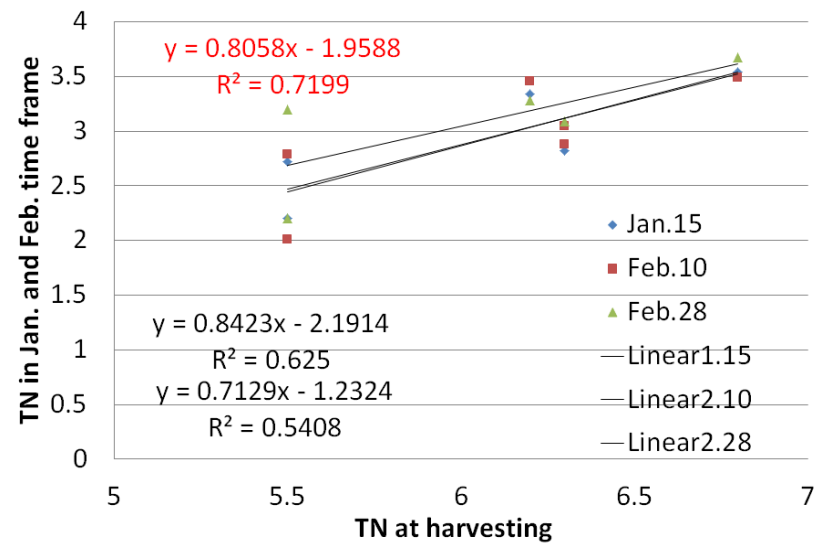

Satellite data acquired in winter is useful for evaluation of

Tea tree vitality which proportional to quality of new tealeaves

Fig. 11. Relation between $\mathrm{TN}$ measured in winter by using visible to near infrared reflectance derived from remote sensing satellite data and $\mathrm{TN}$ at harvest timing 
Not only, can quality of tealeaves but also harvest amount be estimated with the remote sensing satellite data. Fig. 12 shows the relation between TN and TN multiplied by weight of the harvested amount of tealeaves in unit of $\mathrm{kg} / \mathrm{a}$.

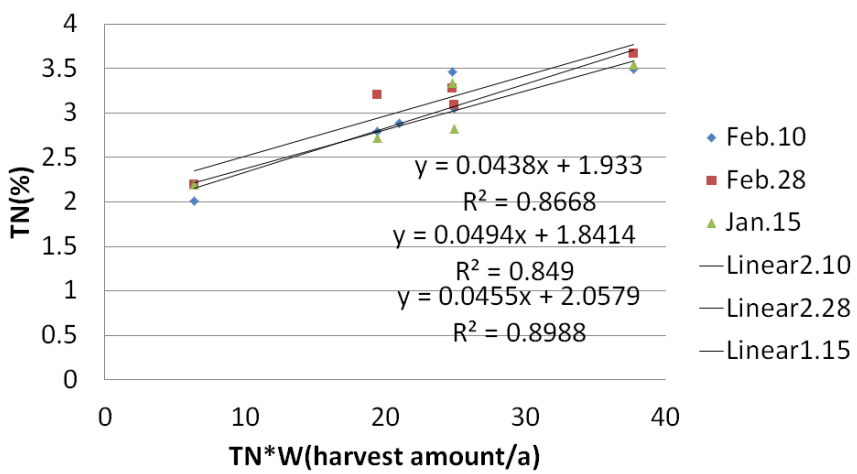

Fig. 12. Relation between TN and TN multiplied by weight of the harvested amount of tealeaves in unit of $\mathrm{kg} / \mathrm{a}$

\section{EXPERIMENTS FOR VIGOR DIAGNOSIS}

\section{A. NDVI Derived from Remote Sensing Data}

Remote sensing data acquisition is key issue for vigor diagnosis of tea trees. In order to check the availability of ASTER/VNIR data with less than $10 \%$ of cloud coverage of search condition, the following available data are retrieved,

- 2007: 7/2, 8/18, 10/23, 11/26, 12/24

- 2008: 1/4, 1/15, 2/10, 2/27, 2/28, 3/29, 4/14, 5/2, 5/16, $6 / 1,7 / 1,7 / 2,8 / 4,8 / 20,9 / 5,10 / 8,11 / 7,12 / 10$

- 2009: 1/11, 2/12, 2/28, 3/16, 4/17, 6/20, 7/6, 8/7, 8/23, 9/24, $10 / 10,10 / 14,11 / 27,12 / 29$

- 2010: $1 / 30,2 / 17,3 / 3,3 / 19,4 / 4$

On the other hand, ASTER/VNIR data acquired on the following dates are selected for vigor diagnosis

2010/3/19, 2011/12/19, 2012/11/3, 2013/12/8, 2014/10/24

One of the examples of NDVI image of Kyushu in Japan derived from the ASTER/VNIR data acquired on 2014/10/24 is shown in Fig.12.

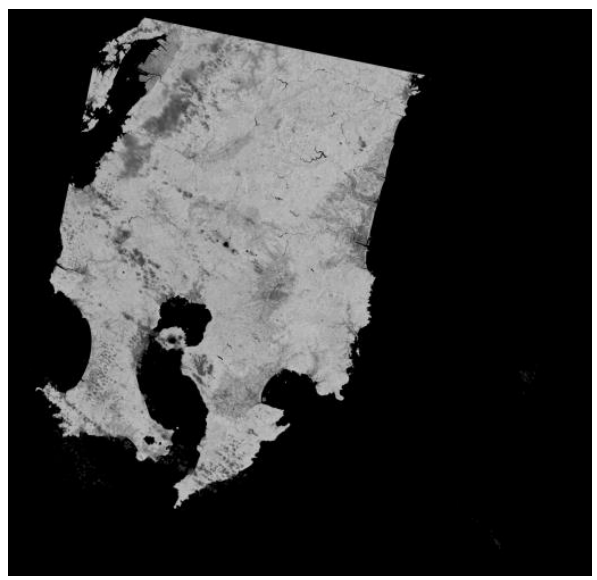

Fig. 13. One of the examples of NDVI image of Kyushu in Japan derived from the ASTER/VNIR data acquired on 2014/10/24

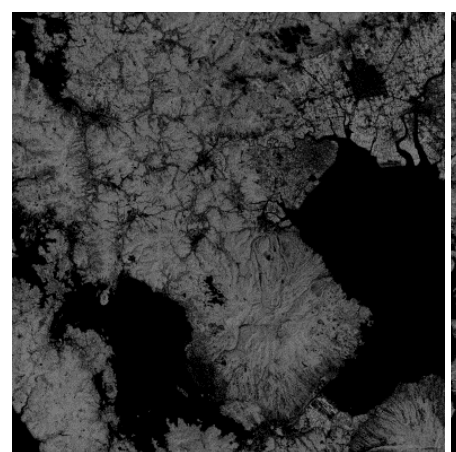

(a) 2010

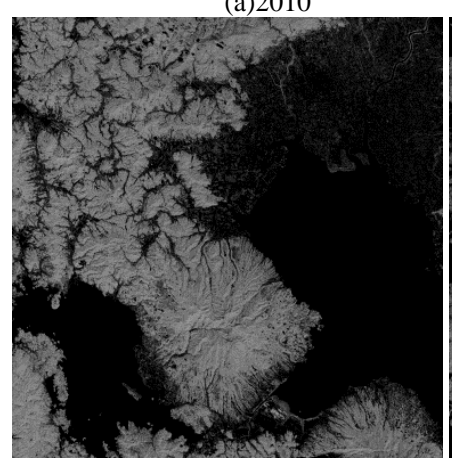

(c)2012

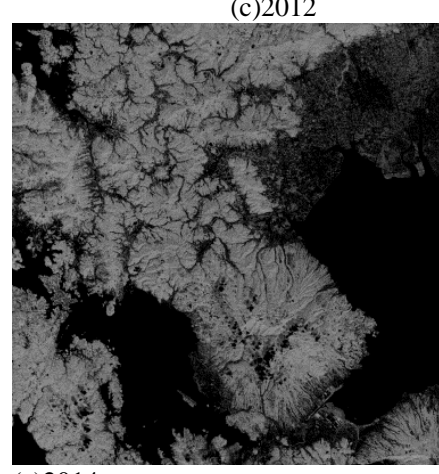

(e) 2014

Fig. 14. NDVI images acquired in 2010 to 2014 for tea tree vigor diagnosis

From these NDVI, tea tree vigor diagnosis can be done based on the previously reduced regressive equations,

$$
\begin{aligned}
& \mathrm{TN}=16.47-6.8672 \\
& \mathrm{~F}-\mathrm{NIR}=-236.18+175.58
\end{aligned}
$$

for TN and fiber content in tealeaves. Table 1 shows the averaged NDVI derived from ASTER/VNIR data and weight (tea product amount for the first harvest tealeaves), income of the tea product (sale), and averaged income per weight (mean sale) each year. The averaged income per weight indicates quality of tealeaves. Because the price of tea product depends on tealeaf quality, the averaged income per weight represents tealeaf quality. Therefore, if NDVI has a high correlation to the averaged income per weight, then it may concluded that tealeaf quality at the harvest timing and tea tree vigor can be estimated remote sensing satellite data. 
TABLE I. AVERAGED NDVI DERIVED FROM ASTER/VNIR DATA AND WeIGHT (TEA PRoduct AMOUNT FOR THE FIRST HARVEST TEALEAVES), INCOME OF THE TEA PRODUCT, AND AVERAGED INCOME PER WEIGHT EACH YEAR

\begin{tabular}{|l|l|l|l|l|}
\hline Year & Mean Sale(JYen/kg) & Weight(kg) & Sale(JYen) & NDVI \\
\hline 2016 & 2434 & 436815 & 1063099512 & \\
\hline 2015 & 2533 & 398899 & 1010606868 & 53.042 \\
\hline 2014 & 2150 & 467239 & 1004526406 & 28.692 \\
\hline 2013 & 2577 & 459787 & 1185080949 & 47.276 \\
\hline 2012 & 2503 & 479307 & 1199574944 & 23.066 \\
\hline 2011 & 2572 & 471395 & 1212486871 & \\
\hline 2010 & 2965 & 470176 & 1394118944 & 56.901 \\
\hline 2009 & 2268 & 494784 & 1122402340 & 30 \\
\hline 2008 & 2457 & 508127 & 1248218686 & 40 \\
\hline 2007 & 2674 & 469883 & 1256342058 & 60 \\
\hline
\end{tabular}

Although NDVI is neither related to the weight of sold amount of tea products, nor the total income per weight of sold amount of tea products, NDVI is related to the averaged income of sold tea products (tealeaf quality) with 0.5627 of $\mathrm{R}$ square value (determination coefficient) as shown in Fig.14 (a), (b) and (c).

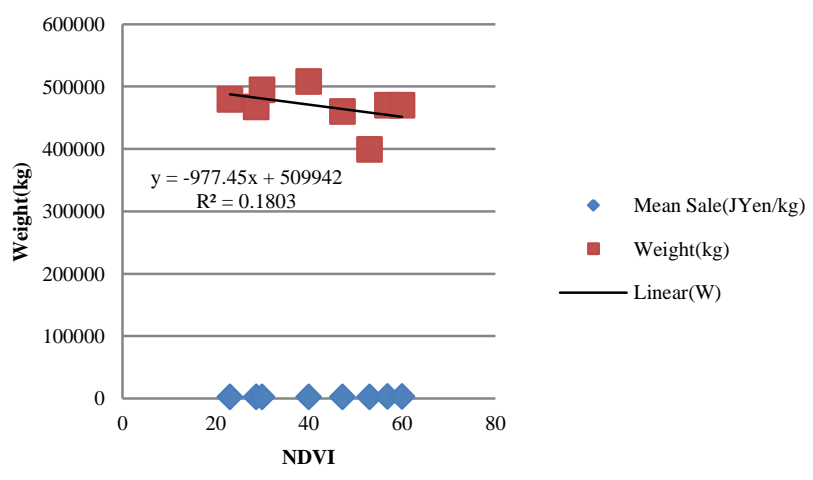

(a)Weight of sold tea product

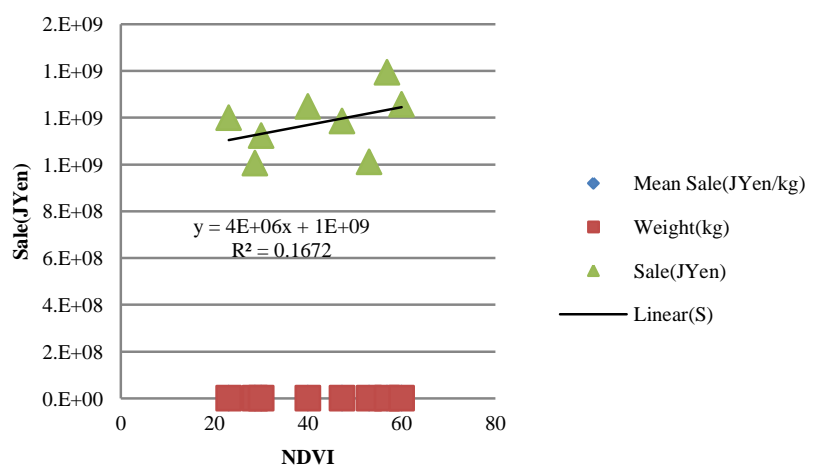

(b)Total income of sold tea products

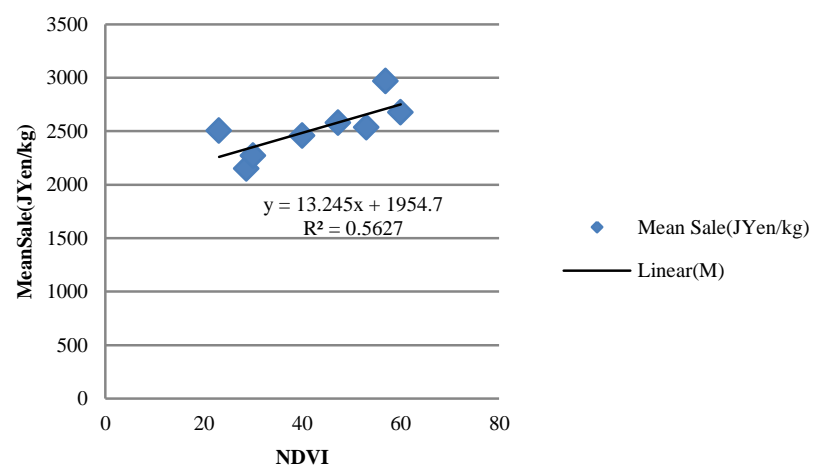

(c)Averaged income of sold tea products

Fig. 15. Relation between NDVI and the averaged income of sold tea products, total income of sold tea products as well as total weight of sold tea products of the first harvested tealeaves

\section{CONCLUSION}

Method for vigor diagnosis of tea trees based on nitrogen content in tealeaves relating to NDVI is proposed. In the proposed method, NIR camera images of tealeaves are used for estimation of nitrogen content in tealeaves. The nitrogen content is highly correlated to Theanine (amid acid) content in tealeaves. Theanine rich tealeaves taste good. Therefore, tealeaves quality can be estimated with NIR camera images. Also, leaf area of tealeaves is highly correlated to NIR reflectance of tealeaf surface. Therefore, not only tealeaf quality but also harvest mount can be estimated with NIR camera images.

Experimental results shows the proposed method does work for estimation of appropriate tealeaves harvest timing with NIR camera images. It is found that NDVI is neither related to the weight of sold amount of tea products, nor the total income per weight of sold amount of tea products. It is also found that NDVI is related to the averaged income of sold tea products (tealeaf quality) with 0.5627 of $\mathrm{R}$ square value (determination coefficient).

\section{ACKNOWLEDGEMENTS}

Author would like to thank Dr. Hideo Miyazaki of Saga Prefecture Tea Research Institute for his efforts for conducting the experiments.

\section{REFERENCES}

[1] J.T.Compton, Red and photographic infrared linear combinations for monitoring vegetation, Journal of Remote Sensing of Environment, 8, 127-150, 1979.

[2] C.Wiegand, M.Shibayama, and Y.Yamagata, Spectral observation for estimating the growth and yield of rice, Journal of Crop Science, 58, 4, 673-683, 1989. 
[3] S.Tsuchida, I.Sato, and S.Okada, BRDF measurement system for spatially unstable land surface-The measurement using spectroradiometer and digital camera- Journal of Remote Sensing, 19, 4, 49-59, 1999.

[4] K.Arai, Lecture Note on Remote Sensing, Morikita-shuppan Co., Ltd., 2000.

[5] K.Arai and Y.Nishimura, Degree of polarization model for leaves and discrimination between pea and rice types of leaves for estimation of leaf area index, Abstract, COSPAR 2008, A3.10010-08\#991, 2008.

[6] K.Arai and Long Lili, BRDF model for new tealeaves and new tealeaves monitoring through BRDF monitoring with web cameras, Abstract, COSPAR 2008, A3.10008-08\#992, 2008.

[7] Greivenkamp, John E., Field Guide to Geometrical Optics. SPIE Field Guides vol. FG01. SPIE. ISBN 0-8194-5294-7, 2004.

[8] Seto R H. Nakamura, F. Nanjo, Y. Hara, Bioscience, Biotechnology, and Biochemistry, Vol.61 issue9 1434-1439 1997.

[9] Sano M, Suzuki M ,Miyase T, Yoshino K, Maeda-Yamamoto, M.,J.Agric.Food Chem., 47 (5), 1906-1910 1999.

[10] Kohei Arai, Method for estimation of grow index of tealeaves based on Bi-Directional reflectance function: BRDF measurements with ground based network cameras, International Journal of Applied Science, 2, 2, $52-62,2011$.

[11] )Kohei Arai, Wireless sensor network for tea estate monitoring in complementally usage with Earth observation satellite imagery data based on Geographic Information System(GIS), International Journal of Ubiquitous Computing, 1, 2, 12-21, 2011.

[12] Kohei Arai, Method for estimation of total nitrogen and fiber contents in tealeaves with ground based network cameras, International Journal of Applied Science, 2, 2, 21-30, 2011.

[13] Kohei Arai, Monte Carlo ray tracing simulation for bi-directional reflectance distribution function and grow index of tealeaves estimation, International Journal of Research and Reviews on Computer Science, 2, 6, 1313-1318, 2011.

[14] K.Arai, Monte Carlo ray tracing simulation for bi-directional reflectance distribution function and grow index of tealeaves estimations, International Journal of Research and Review on Computer Science, 2, 6, 1313-1318, 2012.
[15] K.Arai, Fractal model based tea tree and tealeaves model for estimation of well opened tealeaf ratio which is useful to determine tealeaf harvesting timing, International Journal of Research and Review on Computer Science, 3, 3, 1628-1632, 2012.

[16] Kohei Arai, Method for tealeaves quality estimation through measurements of degree of polarization, leaf area index, photosynthesis available radiance and normalized difference vegetation index for characterization of tealeaves, International Journal of Advanced Research in Artificial Intelligence, 2, 11, 17-24, 2013.

[17] K.Arai, Optimum band and band combination for retrieving total nitrogen, water, and fiber in tealeaves through remote sensing based on regressive analysis, International Journal of Advanced Research in Artificial Intelligence, 3, 3, 20-24, 2014.

\section{AUTHORS PROFILE}

Kohei Arai, He received BS, MS and PhD degrees in 1972, 1974 and 1982, respectively. He was with The Institute for Industrial Science and Technology of the University of Tokyo from April 1974 to December 1978 and also was with National Space Development Agency of Japan from January, 1979 to March, 1990. During from 1985 to 1987, he was with Canada Centre for Remote Sensing as a Post Doctoral Fellow of National Science and Engineering Research Council of Canada. He moved to Saga University as a Professor in Department of Information Science on April 1990. He was a councilor for the Aeronautics and Space related to the Technology Committee of the Ministry of Science and Technology during from 1998 to 2000. He was a councilor of Saga University for 2002 and 2003. He also was an executive councilor for the Remote Sensing Society of Japan for 2003 to 2005. He is an Adjunct Professor of University of Arizona, USA since 1998. He also is Vice Chairman of the Commission-A of ICSU/COSPAR since 2008. He received Science and Engineering Award of the year 2014 from the minister of the ministry of Science Education of Japan and also received the Bset Paper Award of the year 2012 of IJACSA from Science and Information Organization: SAI. In 2016, he also received Vikram Sarabhai Medal of ICSU/COSPAR and also received 20 awards. He wrote 34 books and published 520 journal papers. $\mathrm{He}$ is Editor-in-Chief of International Journal of Advanced Computer Science and Applications as well as International Journal of Intelligent Systsems and Applications. http://teagis.ip.is.saga-u.ac.jp/ 